\title{
Simulation Study on Low Thermal Resistance Materials to Improve Pipe-laying Cable Ampacity
}

\author{
Yanfeng Wang ${ }^{1}$, Wenwei Zhu ${ }^{1}$, Yaodong $\mathrm{Guo}^{2,}$, Zhifeng $\mathrm{Xu}^{2}$, Zhaojian $\mathrm{Wu}^{2}$, Rongjun $\mathrm{Li}^{2}$, Gang Liu ${ }^{2}$ \\ ${ }^{1}$ Guangdong Power Grid Corporation, Guangzhou, Guangdong, China \\ ${ }^{2}$ South China University of Technology, Guangzhou, Guangdong, China
}

\begin{abstract}
Pipe-laying cables have been widely used in the urban power transmission grid. The ampacity of the pipe-laying cables is affected by the thermal conductivity of the filling material, the ratio of the filling material and other factors. For this part of the content, the existing research is not enough. In this paper, a multi-field coupling model for pipe-laying cables is established and the validity of the proposed model is verified by the cable experiment. Based on the proposed multi-field model, three different filling materials have been compared and several influence factors have been investigated. Results show that the filling materials can significantly improve the heat dissipation environment in the pipe and increase the ampacity of the cable. Different filling materials, as well as their filling proportion in the pipe, will ultimately affect the ampacity of the cable. The results can provide guidance in practical engineering application.
\end{abstract}

\section{Introduction}

As an important operating parameter of the transmission lines, the ampacity is not only related to the conductor area of the line itself, the thermal conductivity of the material and other parameters, but also affected by the heat dissipation condition of the external laying environment of the lines. Since the urban underground space resources are limited, it is possible to consider improving the external heat dissipation condition to increase the rated ampacity of the original cable lines. Accordingly, there is no need to replace large crosssection cable cores or increase the number of circuit loops $[1,2]$.

In the pipe-laying method of cable, the high-density polyethylene pipe outside the cable can effectively reduce the possibility of external force damage; however, the additional air layer inside the pipe and the thermal resistance of the pipe wall greatly affect the heat dissipation of the cable. Studies have shown that, compared with the direct buried laying cable lines, the rated ampacity of cables in pipe-laying is significantly reduced [1]. Meanwhile, for some directly buried lines that pass through arterial roads and intersections, for safety reasons, the local pipe-laying structure is required. When calculating ampacity of such lines, the power departments often refer to the method of pipe-laying for calculation. However, its unfavorable heat dissipation condition has become a bottleneck for increasing the ampacity of the entire line and seriously limiting the transmission capacity of the line. Therefore, the study of low thermal resistance filling materials to improve the heat dissipation condition of pipe-laying cables and local pipe-laying cables is of great significance for fully developing the transmission capacity of existing lines. However, some important issues have been neglected in the current research. For example, when filling materials are filled in long laying pipelines, air cells are often blocked by foreign bodies and affect the heat dissipation of the cable.

In this paper, based on the principles of fluid mechanics and heat transfer, combined with the characteristics of air natural convection and solid heat transfer, the COMSOL Multiphysics software is applied and an electromagnetic-thermal-fluid multi-field coupling model of the pipe-laying cable is established. The reliability of the model is verified. On the basis of verifying the reliability of the model, the following studies are conducted, such as the type of filling material, the ratio of the filling material, and the influence of the combination from the above two factors on the ampacity of pipe-laying cables. The study can provide guidance for actual engineering applications.

\section{Construction of pipe-laying cable model}

\subsection{Modeling assumptions}

For the pipe-laying cable, its heat transfer methods are not only the heat conduction and heat radiation between the cable, the pipe, and the soil, but also the natural convection heat dissipation by the air in the pipe. Besides, the internal material of the cable will generate heat that affects the overall temperature field distribution under the changing electromagnetic field excited by the alternating current. Therefore, it is necessary to establish 
an electromagnetic-thermal-fluid coupling model to analyze the pipe-laying cable [3].

To simplify the calculation model, the following assumptions are required.

a) Assuming that the cable is infinitely long and does not consider the cable distortion, the actual threedimensional structure is simplified to a two-dimensional model.

b) The materials of each layer in cable, the pipe, the filling material in the pipe, and the soil are all isotropic media, and the physical parameters are all constant.

d) The power frequency electromagnetic field of the cable is treated as a steady-state field, the time term is not included in the control equation, and the influence of the displacement current is ignored.

\subsection{Establishment of two-dimensional model of pipe-laying cable}

The cable contains three main heat sources: conductor loss, insulation loss and metal sheath loss. Compared with conductor loss, the insulation loss and metal sheath loss of the cable are relatively small. Therefore, only the conductor loss of the cable is considered in the simulation model, and the size of the heat source is calculated by the formula in IEC-60287:

$$
\begin{gathered}
W_{C}=I^{2} R \\
R=R_{0}\left[1+\alpha_{20}(T-20)\right]\left(1+Y_{S}+Y_{P}\right)
\end{gathered}
$$

In the above equations, $R_{0}$ is the $\mathrm{DC}$ resistance of the conductor at $20^{\circ} \mathrm{C}, \Omega ; \alpha_{20}$ is the temperature coefficient of copper at $20^{\circ} \mathrm{C}$ for each absolute temperature; $T$ is the steady-state temperature of the conductor, ${ }^{\circ} \mathrm{C} ; Y_{S}$ is the skin effect coefficient; $Y_{p}$ is the proximity effect coefficient.

Combined with the geometric structure of the aforementioned pipe-laying cable, in this paper, a twodimensional geometric model of the pipe-laying cable is established, as shown in Fig. 1. In the simulation model, a single $110 \mathrm{kV}$ cable is laid in a high-density polyethylene (HDPE) pipe with an outer diameter of 200 $\mathrm{mm}$ and an inner diameter of $194 \mathrm{~mm}$. The structural parameters of the cable are shown in Table 1. The voltage level is $110 \mathrm{kV}$. The laying environment of the cable is shown in Table 2. In the model, the left and right boundaries are $2 \mathrm{~m}$ away from both sides of the laying pipe, the lower boundary is $2 \mathrm{~m}$ away from the underside of the laying pipe, and the buried depth is $1.2 \mathrm{~m}$.

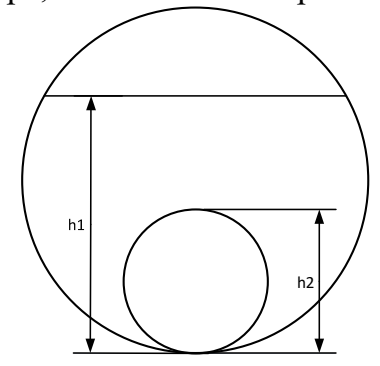

Fig. 1. Two-dimensional simulation model of pipe-laying cable
Table 1. Structural parameters of cable

\begin{tabular}{|c|c|c|c|}
\hline & Materials & $\begin{array}{c}\text { Outer } \\
\text { diameter/m } \\
\mathbf{~ m}\end{array}$ & $\begin{array}{c}\text { heat } \\
\text { conductivity } \\
\text { coefficient / } \\
\mathbf{W}^{-\mathbf{1}} \mathbf{K}^{\mathbf{1}}\end{array}$ \\
\hline Conductor & $\mathrm{Cu}$ & 30.3 & 400 \\
\hline $\begin{array}{c}\text { Insulation } \\
\text { Water- } \\
\text { blocking } \\
\text { tape }\end{array}$ & $\begin{array}{c}\text { Semi- } \\
\text { buffer water } \\
\text { barrier layer }\end{array}$ & 68.0 & 0.40 \\
\hline $\begin{array}{c}\text { corrugated } \\
\text { metal } \\
\text { sheath }\end{array}$ & Al & 88.4 & 0.1667 \\
\hline $\begin{array}{c}\text { Outer } \\
\text { sheath }\end{array}$ & PE & 99.1 & 238 \\
\hline
\end{tabular}

Table 2. Cable laying parameters

\begin{tabular}{|c|c|}
\hline Laying parameters & Value \\
\hline Buried depth/m & 1.2 \\
\hline Thermal conductivity of soil $/ \mathbf{W} \cdot \mathbf{m}^{-\mathbf{1}} \cdot \mathbf{K}^{-1}$ & 2.0 \\
\hline Air temperature/K & 287.15 \\
\hline convective heat transfer coefficient / \\
$\mathbf{W} \cdot\left(\mathbf{m}^{\mathbf{2}} \cdot \mathbf{K}\right)^{-1}$ & 12.5 \\
\hline Deep soil temperature/K & 287.15 \\
\hline
\end{tabular}

The boundary conditions of the cable heat transfer problem can be summarized into three categories: the first category is the known boundary temperature; the second category is the known boundary normal heat flux density; the third category is the convective boundary conditions. The governing equations of the three types of boundary conditions are shown in equations (3).

$$
\left\{\begin{array}{l}
\text { I: }\left.T(x, y)\right|_{\Gamma_{1}}=\left.f(x, y)\right|_{\Gamma_{1}} \\
\text { II: }-\left.k \frac{\partial T}{\partial n}\right|_{\Gamma_{2}}=q \\
\text { III: }-\left.k \frac{\partial T}{\partial n}\right|_{\Gamma_{3}}=\left.h\left(T-T_{f}\right)\right|_{\Gamma_{3}}
\end{array}\right.
$$

In the equations, $\Gamma_{1}, \Gamma_{2}, \Gamma_{3}$ are the integral boundaries of the three types of boundary conditions, $k$ is the thermal conductivity of the soil, $\mathrm{W} /(\mathrm{m} \cdot \mathrm{K}) ; h$ is the convective heat transfer coefficient between the surface soil and air.

\section{Calculation examples}

With the above-mentioned cable model and experimental environment as simulation conditions, a multi-field coupling of electromagnetic-thermal-fluid model is used for calculation, and the simulation results are compared with the experimental results to verify the accuracy of the model. 
Reference [2] conducted experiments for non-filling pipe-laying cable and full-filled pipe-laying cable. The simulation data and experimental data records are shown in Table 3.

Table 3. Comparison of simulation data and experimental data

\begin{tabular}{|c|c|c|c|}
\hline \multirow{2}{*}{ Current/A } & \multicolumn{3}{|c|}{ Temperature of Non-filling pipe } \\
\cline { 2 - 4 } & Experiment & Simulation & Error \\
\hline 1130 & 91.3 & 87.2 & $-4.49 \%$ \\
\hline 1290 & 118.6 & 116 & $-2.19 \%$ \\
\hline \multirow{2}{*}{ Current/A } & \multicolumn{2}{|c|}{ Temperature of Full-filled pipe } \\
\cline { 2 - 4 } & Experiment & Simulation & Error \\
\hline 1130 & 74.0 & 74.2 & $+0.27 \%$ \\
\hline 1290 & 90.5 & 97.3 & $+7.51 \%$ \\
\hline
\end{tabular}

Fig. 2 shows the COMSOL simulation result of the pipe-laying cable without filling material in the pipe, where the core temperature of the cable reaches $90^{\circ} \mathrm{C}$ when the 1130A current flowing through the cable.

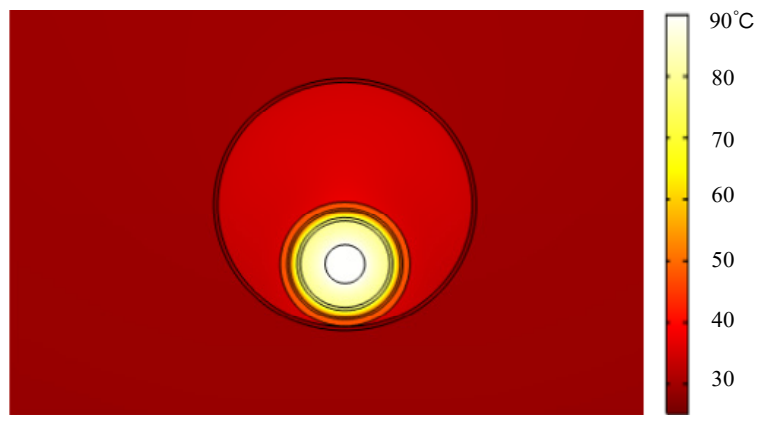

Fig. 2. Non-filling pipe-laying cable

In Table 3, under the same conditions, the average error of the four verification experiments is $3.6 \%$. Due to a rainfall during the experiment in Reference [2], the soil thermal conductivity, air temperature, soil temperature, etc. fluctuate greatly. Therefore, the experimental error of the 1290A fully-filled segment is relatively large, but the overall average error is less than $5 \%$, which meets the needs of the project, thus verifying the accuracy of the model.

\section{Analysis of influencing factors}

In this chapter, aiming at the lack of study on the high thermal conductivity filling materials in pipe-laying cables, the change of cable temperature field is studied on the following aspects, that is, the type of filling material, the proportion of the filling material and the combination from the above two factors. Also taking the cable with the cable structure parameters in Table 1 as an example, the COMSOL Multiphysics is applied to calculate the core temperature of the cable when the above-mentioned conditions change but the ampacity remains the same.

\subsection{Influence of filling material type}

For the purpose to increase the ampacity of the pipelaying cable, a material with high thermal conductivity is usually filled between the pipe and the cable. At present, the low thermal resistance filling materials used in pipelaying cables mainly include $\mathrm{SH}, \mathrm{SBM}$, and water $[2,4]$. In Table 4, when the ampacity of the cable core is $1150 \mathrm{~A}$, the influence of different filling materials on the conductor temperature of the pipe-laying cable is listed. It can be found that all three materials have effectively improved the heat dissipation environment of the pipelaying cable. The temperature of the cable has dropped by about $10^{\circ} \mathrm{C}$ during stable operation. Where, the $\mathrm{SH}$ gel has the greatest effect on improving the pipe-laying cable, which makes the cable temperature drop by $13.4^{\circ} \mathrm{C}$ during stable operation.

Table 4. Influence of different filling materials on cable conductor temperature at $1150 \mathrm{~A}$

\begin{tabular}{|c|c|c|c|c|}
\hline Filling materials & Air & SH gel & SBM & Water \\
\hline $\begin{array}{c}\text { heat conductivity / } \\
\mathbf{W} \cdot \mathbf{m}^{-1} \cdot \mathbf{K}^{\mathbf{1}}\end{array}$ & 0.026 & 2 & 0.95 & 0.667 \\
\hline Temperature/ ${ }^{\circ} \mathbf{C}$ & 90.4 & 76.8 & 79.0 & 81.0 \\
\hline
\end{tabular}

\subsection{Influence of proportion of filling materials}

In the process of filling the low thermal resistance material, it is very likely that the material cannot be completely filled somewhere in the pipe due to insufficient filling, which will affect the heat dissipation of the cable and limit the ampacity of the cable. Therefore, it is necessary to study the influence of the proportion of the filling material on the temperature of the cable conductor. Ratio of defined filling material=filling height/cable outer diameter. In addition, in order to save resources and reduce material costs, it will be of practical significance to study the influence of the proportion of filling materials on the ampacity of the pipe-laying cable.

Table 5 shows the influence of different filling ratios on the temperature of the cable conductor when the current is $1150 \mathrm{~A}$ and the filling material is SH gel. When the filling ratio is 1.96 , it is considered as full filling. In Table 5, as the proportion of the filling material increases, the temperature of the cable conductor becomes lower and lower. When the filling ratio is 0.5 , the temperature has dropped by $7.4^{\circ} \mathrm{C}$. The filling is continued until the temperature drops by $12.4^{\circ} \mathrm{C}$ after full filling. In the pipe, the heat dissipation efficiency of heat conduction is better than that of natural convection. Increasing the proportion of the filling material can reduce the air content in the pipe and increase the contact area of heat conduction. Compared with the air layer with high thermal resistance, the low thermal resistance filling material can effectively reduce the environmental heat resistance, thereby reducing the temperature of the cable. 
Table 5. Relationship between temperature of cable conductor and ratio of filling material

\begin{tabular}{|l|c|c|c|c|c|}
\hline $\begin{array}{l}\text { Ratio of filling } \\
\text { material }\end{array}$ & 0 & 0.5 & 1 & 1.5 & 1.96 \\
\hline Temperature $/{ }^{\circ} \mathbf{C}$ & 90.3 & 82.9 & 80.7 & 79.5 & 77.9 \\
\hline
\end{tabular}

\subsection{Filling material--filling material ratio}

In practice, the temperature of the cable conductor is not only affected by the above single factor, but is affected by multiple factors. Therefore, it is necessary to study the influence of multiple factors on the temperature of the cable conductor. When the filling material is water, $\mathrm{SH}$ gel, and SBH material, the combined effect of "filling material--filling material ratio" on the temperature of the pipe-laying cable is shown in Fig. 3.

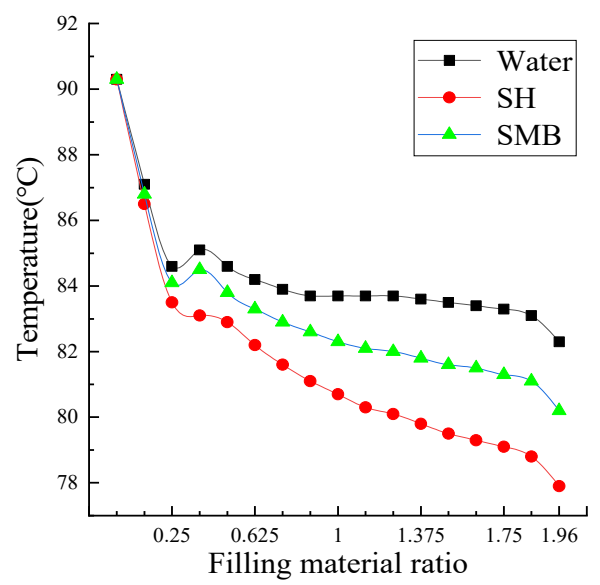

Fig. 3. Influence of Filling material--filling material ratio combination on temperature

From Fig. 3, after filling different materials, as the filling ratio increases, the temperature of the cable conductor first drops quickly and then slowly. Where, when the filling ratio is 0.25 , the temperature has dropped by about $6^{\circ} \mathrm{C}$. Moreover, if water is used as the filling material in the pipe, when the filling ratio exceeds 0.25 , continuing to increase the filling ratio has almost no effect on the temperature of the cable conductor.

\section{Conclusions}

a) The COMSOL Multiphysics software is used to carry out finite element analysis of the cable, and the unfilled, partially filled and fully filled temperature field calculation models of the pipelaying cable are established. Compared with the experiment, the average error is $3.6 \%$, and it is believed that the error comes from unknown natural environmental factors in the field experiment. The average error is less than $5 \%$, indicating that the multi-field coupling of electromagnetic-thermalfluid model constructed in this paper has high accuracy.

b) The change in the cable ampacity can be obtained from the change in the temperature of the cable conductor. To increase the ampacity of the pipe- laying cable, the filling materials with high thermal conductivity can be filled. At present, the low thermal resistance filling materials used in pipelaying cables are mainly SH, SBM, and water, and their thermal conductivity are $2,0.95$, and $0.667 \mathrm{~W}$. $\mathrm{m}^{-1} \cdot \mathrm{K}^{-1}$, respectively. The simulation model results show that under the load of $1150 \mathrm{~A}$, filling the above three materials can let the temperature drop by $13.4^{\circ} \mathrm{C}, 11.4^{\circ} \mathrm{C}$, and $9.4^{\circ} \mathrm{C}$, respectively. Therefore, these materials can significantly improve the heat dissipation environment in the pipe and increase the ampacity of the cable.

c) When other conditions remain unchanged, the larger the filling ratio of the material, the lower the conductor temperature of the cable. Further, when the filling ratio of the filling material increases from 0 to 0.25 , the temperature of the cable conductor drops most obviously. After that, the increase of the material filling ratio has a relatively small effect on the temperature of the cable. As a result, considering practical issues such as the cost of the filling material, an appropriate filling ratio can be selected to obtain the highest efficiency.

\section{Acknowledgements}

This work was supported by planning project of Guangdong power grid company: Study on the ampacity of high voltage cable line under typical working conditions(031000QQ00200009).

\section{References}

1. R. Hoerauf, Ampacity application considerations for underground cables, IEEE Trans. Ind. Appl., 52, 4638-4645, (2016).

2. M. Zhang, Y.B. Fan, S.H. Liu, Improvement in Power Cables Ampacity in Ducts by Using Low Thermal Resistivity Backfill Material, High Voltage Engineering, 42(8), 2394-2398, (2016).

3. R.A. Hartlein, W.Z. Black, Ampacity of Electric Power Cables in Vertical Protective Risers, IEEE Transactions on Power Apparatus and Systems, 102(6), 1678-1686, (1983).

4. P. Ocłoń, M. Bittelli, P. Cisek, E. Kroener, M. Pilarczyk, D. Taler, R.V. Rao, A. Vallati, The performance analysis of a new thermal backfill material for underground power cable system, Applied Thermal Engineering, 108, 233-250, (2016).

5. P. Vaucheret, R.A. Hartlein, W.Z. Black, Ampacity derating factors for cables buried in short segments of conduit, IEEE Transactions on power delivery, 20(2), 560-565, (2005). 